\title{
PENGARUH KUALITAS PELAYANAN TERHADAP KEPUASAN KONSUMEN DI TOKO INTAN MARKET LINTAS MELAWI SINTANG
}

\author{
EKA SURYANI ${ }^{1}$, AVELIUS DOMINGGUS SORE ${ }^{2}$, YUNITA ASTIKAWATI ${ }^{3}$ \\ 1ekasuriyati994@gmail.com \\ 2avelius12@gmail.com \\ 3yunitaakun@gmail.com
}

STKIP Persada Khatulistiwa

\begin{abstract}
The general objective of this study is to determine the effect of service quality on customer satisfaction at the Intan Market Lintas Melawi Sintang. The research approach used a descriptive quantitative approach. form of research is simple linear regression. The population in this research are all consumers who have been customers of the Intan Market Lintas Melawi Sintang. The sampling technique used is a non-probability sampling technique with a type of incidental sampling. Data collection techniques used are indirect communication techniques, and documentation techniques with data collection tools in the form of questionnaires and documents. Based on the analysis results obtained: The criteria of service quality at the the Intan Market Lintas Melawi Sintang are sufficient. 2) Customer satisfaction has good criteria. 3) Based on a simple regression test, it is proven that service quality has a positive effect on customer satisfaction with a determination coefficient of $36.02 \%$.
\end{abstract}

Key word: Quality, Service, and Satisfaction.

\begin{abstract}
ABSTRAK
Tujuan umum penelitian ini adalah untuk mengetahui pengaruh kualitas pelayanan terhadap kepuasan konsumen pada Pasar Intan Lintas Melawi Sintang. Pendekatan penelitian menggunakan pendekatan kuantitatif deskriptif. Bentuk penelitiannya adalah regresi linier sederhana. Populasi dalam penelitian ini adalah seluruh konsumen yang pernah menjadi pelanggan Pasar Intan Lintas Melawi Sintang. Teknik pengambilan sampel yang digunakan adalah teknik non-probability sampling dengan jenis pengambilan sampel insidental. Teknik pengumpulan data yang digunakan adalah teknik komunikasi tidak langsung, dan teknik dokumentasi dengan alat pengumpulan data berupa angket dan dokumen. Berdasarkan hasil analisis diperoleh: Kriteria kualitas pelayanan di Pasar Intan Lintas Melawi Sintang sudah cukup. 2) Kepuasan pelanggan memiliki kriteria yang baik. 3) Berdasarkan uji regresi sederhana terbukti kualitas pelayanan berpengaruh positif terhadap kepuasan konsumen dengan koefisien determinasi 36,02\%.
\end{abstract}

Kata Kunci: Kualitas, Pelayanan, dan Kepuasan 


\section{PENDAHULUAN}

Perkembangan usaha tempat perbelanjaan sangat ketat saat ini mengharuskan masingmasing pengusaha mampu membaca segmen pasar dan menunjukan keunggulannya. Perkembangan usaha ini menyebabkan timbulnya berbagai jenis usaha yang menjadi alternatif bagi konsumen dalam memilih tempat berbelanja. Para pengelolah tempat perbelanjaan dituntut untuk lebih mengikuti perkembangan pasar sebagai dasar penetapan keputusan pelanggan. Perusahan harus mampu menciptakan citra tersendiri dan mengupayakan strategi pemasaran yang baik. Citra kualitas yang baik bukan dilihat dari persepsi pihak perusahaan melainkan berdasar pada persepsi pelanggan (Suharyadi, 2018).

Citra ini membentuk kualitas layanan yang diberikan oleh usaha untuk melayani kebutuhan dan keingan konsumen. Menurut Tjiptono (2014: 353), "kualitas pelayanan adalah suatu sikap atau cara dalam melayani pelanggan supaya pelanggan mendapatkan kepuasan yang meliputi kecepatan, ketepatan, keramahan dan kenyamanan". Apabila konsumen tidak mendapatkan pelayanan yang baik maka konsumen akan merasa kecewa dan menimbulkan keluhan. Apabila pelanggan merasa kualitas pada sebuah layanan cukup baik maka pelanggan tersebut berpeluang datang kembali untuk berbelanja. Pelanggan yang mempunyai pengalaman yang memuaskan kecenderungannya akan datang kembali dan biasanya akan membawa teman atau saudara (Ranto, 2017). Namun sebaliknya jika layanan kurang baik maka akan mengakibatkan pelangan engan untuk berbelanja kembali. Hal in mencerminkan bahwa konsumen menjadi faktor penentu pada keberlangsungan usaha.

Apabila konsumen tidak menyukai layanan dan menyebabkan ketidakpuasan maka akan menyebabkan usaha kehilangan sumber penghasilannya. Ini menjadi benang merah yang harus menjadi perhatian para pengusaha untuk tetap meningkatkan kualitas layanan sehingga keberlangsungan usaha tetap terjaga. Toko Intan Market merupakan salah satu usaha ritel yang cukup besar di kota sintang dan telah memikik berbagai cabang di dalam maupun diluar kota. Toko yang telah memiliki pangsa pasar ini tentu tidak lepas dari persaingan usaha dibidang sejenis. Toko ini telah mempertahankan konsumennya dikondisi persaingan yang ketat. Toko ini memiliki layanan yang prima dibandingkan usaha sejenisnya. Namun tentu saja konsumen dapat berpindah jika konsumen merasa kurang puas dengan layanan usaha. Oleh karena itu perlu dikaji tentang kepuasan pelangan dari aktivitas pelayanan pada Toko Intan Market ini.

\section{Permasalaham dan Tujuan}

Berdasarkan latar belakang yang telah diuraikan di atas maka peneliti akan melakukan analisa mengenai pengaruh kualitas pelayanan terhadap kepuasan konsumen di Toko Intan 
Market Lintas Melawi Sintang Tahun 2020. Tujuan penelitian ini adalah untuk memberikan

bukti empris tentang pengaruh kualitas pelayanan terhadap kepuasan konsumen di Toko Intan Sintang

Market Lintas Melawi Sintang Tahun 2020. Selain itu, harapannya hasil penelitian dapat menjadi masukan yang berarti bagi dunia usaha terkhusus Toko Intan Market Lintas Melawi Sintang untuk memperhatikan kualitas layanan konsumen.

\section{TINJAUAN TEORITIS}

\section{Kualitas Pelayanan}

Secara etimologis, pelayanan berasal dari kata layan yang berarti membantu menyiapkan atau mengurus apa-apa yang diperlukan seseorang, kemudian pelayanan dapat diartikan sebagai perihal atau cara melayani servis atau jasa. Adapun pelayanan adalah segala kegiatan pelayanan yang dilakukan oleh penyelenggara pelayanan publik sebagai upaya pemenuhan kebutuhan publik dan pelaksanaan ketentuan peraturan perundang-undangan (Mahmudi, 2015). Adapaun Indikator Kualitas Pelayanan menurut Zeithhaml, Parasuraman dan Berry (Hardiansyah, 2011) untuk mengetahui kualitas pelayanan yang dirasakan secara nyata oleh konsumen, ada indikator kualitas pelayanan yang terletak pada lima dimensi kualitas pelayanan, yaitu:

1. Berwujud (tangible), adalah penampilan fasilitas fisik, peralatan, personil dan perlengkapan operasional suatu perusahaan dalam menunjukkan eksistensinya kepada pihak eksternal.

2. Kehandalan (reliability), adalah kemampuan untuk melaksanakan pelayanan yang semestinya secara tepat sesuai yang dijanjikan dengan akurat dan terpecaya.

3. Ketanggapan (responsiveness) adalah keinginan yang diberikan perusahaan untuk membantu konsumen dan memberikan pelayanan yang cepat dengan penyampaian informasi yang jelas.

4. Keyakinan (assurance) adalah pengetahuan dan keramahan karyawan serta kemampuannya untuk memberikan kesan dapat dipercaya dan penuh keyakinan untuk menumbuhkan rasa percaya pada pelanggan terhadap perusahaan.

5. Kepedulian (emphathy) adalah rasa memiliki rasa memperhatikan dan memelihara pada masing - masing pelanggan atau konsumen

\section{Kepuasan Konsumen}

Kata kepuasan atau satisfaction berasal dari bahasa latin "satis" (artinya cukup baik, memadai) dan "facio" (melakukan atau membuat). Secara umum, kepuasan adalah perasaan 
senang atau kecewa yang timbul karena membandingkan kinerja yang dipersepsikan produk

(atau hasil) terhadap mereka (Keller, 2008). Adapun yang umumnya digunakan untuk Sintang

Mengukur Kepuasan Konsumen menurut Kotler sebagaimana dikutip oleh Yamit (2002) menyatakan ada beberapa metode yang digunakan untuk mengukur kepuasan konsumen yaitu:

1. Sistem pengaduan

Sistem ini memberikan kesempatan kepada pelanggan untuk memberikan saran, keluhan dan bentuk ketidakpuasan lainnya dengan cara menyediakan kotak saran.

2. Survei pelanggan

Survei pelanggan merupakan cara yang umum digunakan dalam mengukur kepuasan pelanggan, misalnya, melalui surat pos, telepon, atau wawancara secara langsung.

3. Panel pelanggan

Perusahaan mengundang pelanggan yang setia terhadap produk dan mengundang pelanggan yang telah berhenti membeli atau telah pindah menjadi pelanggan perusahaan lain. Apabila pelanggan yang telah berhenti membeli (customer loss rate) meningkat hal ini menunjukkan kegagalan perusahaan dalam memuaskan pelanggan.

\section{Indikator Kepuasan Konsumen}

Menurut Hawkins dan Lonney yang dikutip dalam Tjiptono indikator pembentuk kepuasan terdiri dari:

1. Kesesuaian harapan. Merupakan tingkat kesesuaian antara kinerja produk yang diharapkan oleh pelanggan dengan yang dirasakan oleh pelanggan, meliputi:

a. Produk yang diperoleh sesuai atau melebihi dengan yang diharapkan.

b. Pelayanan oleh karyawan yang diperoleh sesuai atau melebihi dengan yang diharapkan.

c. Fasilitas penunjang yang didapat sesuai atau melebihi dengan yang diharapkan.

2. Minat berkunjung kembali. Merupakan kesedian pelanggan untuk berkunjung kembali atau melakukan pembelian ulang terhadap produk terkait, meliputi:

a. Berminat untuk berkunjung kembali karena pelayanan yang diberikan oleh karyawan memuaskan.

b. Berminat untuk berkunjung kembali karena nilai dan manfaat yang diperoleh setelah mengkonsumsi produk.

c. Berminat untuk berkunjung kembali karena fasilitas penunjang yang disediakan memadai. 
3. Kesediaan merekomendasikan. Merupakan kesediaan pelanggan untuk

merekomendasikan produk yang telah dirasakannya kepada teman atau keluarga, meliputi:

a. Menyarankan teman atau kerabat untuk membeli produk yang ditawarkan karena pelayanan yang memuaskan.

b. Menyarankan teman atau kerabat untuk membeli produk yang ditawarkan karena fasilitas penunjang yang disediakan memadai.

c. Menyarankan teman atau kerabat untuk membeli produk yang ditawarkan karena nilai atau manfaat yang didapat setelah mengkonsumsi sebuah produk jasa.

\section{METODE PENELITIAN}

\section{Variable penelitian}

Variable penelitian terdiri Variabel terikat dan Variabel bebas. variabel bebas adalah variabel yang memberikan pengaruh terhadap variabel terikat. Variabel bebas dalam penelitian ini adalah kualitas pelayanan (X). Variabel terikat merupakan variabel yang keberadaannya dipengaruhi oleh variabel bebas. Variabel terikat dalam penelitian ini adalah kepuasan konsumen (Y).

\section{Jenis dan sumber data}

Jenis data dalam penelitian ini merupakan data kuantitatif. Data penelitian diperoleh dari primary data yaitu dari pelanggan. Data ini diperoleh dari konsumen yang sedang berbelanja pada Toko Intan Market Lintas Melawi.

\section{Teknik Pengumpulan Data}

Kecermatan dalam memilih dan menyusun teknik dan alat pengumpulan data ini sangat berpengaruh pada obyektivitas hasil penelitian. Teknik pengumpulan data yang dianggap sesuai dengan rumusan masalah yang akan diteliti adalah teknik komunikasi tidak langsung, dan teknik dokumentasi.

\section{Populasi dan sampel}

Populasi dalam penelitan ini adalah seluruh konsumen yang pernah menjadi pelanggan atau melakukan transaksi di Toko Intan Market Lintas Melawi Sintang Tahun 2020. Teknik sampling yang digunakan dalam menentukan sampel pada 
penelitian ini menggunakan insidental sampling. Insidental sampling adalah teknik penentuan sampel berdasarkan kebetulan, yaitu siapa saja yang secara kebetulan atau insidental bertemu dengan peneliti dapat digunakan sebagai sampel, bila dipandang orang yang kebetulan ditemui itu cocok sebagai sumber data (Sugiyono, 2015).

\section{Teknik analisis data}

Analisis dalam penelitian ini menggunakan beberapa tahap. Pertama angket dianalisis menggunakan uji validitas instrumen dan uji reliablitas istrumen. Kedua, analisis deskriptif untuk menafsirkan hasil angket. Ketiga, analisis statistic meliputi uji normalitas, uji lineritas, uji homogenitas, dan uji regresi.

\section{HASIL PENELITIAN}

Penelitian yang menggali tentang hubungan antara kualitas pelayanan dengan kepuasan konsumen ini di laksanakan di Toko Intan Market Lintas Melawi Sintang. sebelum melaksanakan penelitian ada beberapa hal yang harus dipersiapkan antara lain: Membuat kisi-kisi angket dan angket kualitas pelayaan dan kepuasan pelanggan, memvalidasikan angket kepada tim ahli hingga angket mendapat keterangan Layak Digunakan sebagai instrumen penelitian kemudian dan angket tersebut diuji reliabilitasnya dengan cara diujicobakan kepada selain sampel. Uji coba dilakukan di took sejenis yaitu Toko Intan Market Sungai Durian. Penelitian ini dilakukan sejak tanggal 16 septermber 2020 hingga 01 oktober 2020. Hasil penelitian telah dioleh selama waktu penelitian dan dijabarkan sebagai berikut:

\section{Uji coba angket}

Angket yang digunakan wajib melalui tahap uji coba dengan berbantuan analisis statistic. Penelitian ini menggunakan SPSS 23 dalam analisis data. Uji validitas angket diperoleh indicator kualitas layanan yang dinyatakan dalam pernyataan angket sebanyak 31 diketahui terbatar 2 butir angket yang tidak valid. Indicator kepuasan layanan terdiri dari 25 pernyataan diketahui 1 butir yang tidak valid. Uji reabilitas diukur menggunakan koefisien reabilitas data. Dari hasil analisis diketahui bahwa data bersifat reabel. Berikut tabel reabilitas angket: 
Tabel 1

Hasil SPSS 23 Uji Reliabilitas

\begin{tabular}{cccc}
\hline Variabel & Nilai Alpha & $\begin{array}{c}\text { Cronbach } \\
\text { Alpha }\end{array}$ & Keterangan \\
\hline Kualitas Pelayanan (X) & 0,60 & 0,926 & Reliabel \\
Kepuasan Konsumen (Y) & 0,60 & 0,949 & Reliabel \\
\hline
\end{tabular}

Sumber: hasil pengolahan data primer, 2020

Angket Kualitas Pelayanan

Angket yang digunakan untuk mengetahui kualitas pelayanan per indikator disajikan pada Tabel 2.

Tabel 2

Hasil Angket Kualitas Pelayanan Per Indikator

\begin{tabular}{llc}
\hline \multicolumn{1}{c}{ Indikator } & \multicolumn{1}{c}{ Nomor Angket } & Persentase \\
\hline Berwujud (tangible) & $1,2,3,4,5,6,7,8.9,10$, dan 11 & $70,36 \%$ \\
Kehandalan (reliability) & $12,13,14,15,16$, dan 17 & $68,5 \%$ \\
Ketanggapan & $18,19,20$, dan 21 & $96,67 \%$ \\
(responsiveness) & & \\
Keyakinan (assurance) & $22,23,24,25$, dan 26 & $67,64 \%$ \\
Kepedulian (emphathy) & 27,28, dan 29 & $68,33 \%$ \\
& Jumlah Seluruh Indikator & $344,3 \%$ \\
\multicolumn{2}{c}{ Persentase Rata-Rata Dari Ke 5 Indikator } & 5 \\
& Kriteria & $68,85 \%$ \\
\end{tabular}

Sumber: hasil pengolahan data primer, 2020)

Angket Kepuasan Konsumen

Informasi mengenai kepuasan konsumen diketahui dengan cara mengumpulkan data berupa angket yang disajikan pada Tabel 3.

Tabel 3

Hasil Angket Kepuasan Konsumen Per Indikator

\begin{tabular}{llc}
\hline \multicolumn{1}{c}{ Indikator } & \multicolumn{1}{c}{ Nomor Angket } & Persentase \\
\hline Kesesuaian harapan & $1,2,3,4,5,6,7,8$, dan 9 & $82,8 \%$ \\
Minat berkunjung kembali & $10,11,12,13,14,15,16,17$, dan 18 & $78,9 \%$ \\
Kesediaan & $19,20,21,22,23$, dan 24 & $77,4 \%$ \\
merekomendasikan & & \\
\multicolumn{2}{c}{ Jumlah Seluruh Indikator } & $79,7 \%$ \\
& Priteria & Baik \\
\hline
\end{tabular}

Sumber: hasil pengolahan data primer, 2020 
Analisis statistik

Pelayanan, dan

Kepuasan,

Sintang

Analisis statistik terdiri dari uji prasyarat dan uji regresi sederhana. Adapun kedua uji tersebut dijabarkan sebagai berikut:

1. Uji prasyarat

Uji normalitas. Hasil analisis pra syarat (uji normalitas) data hasil angket kualitas pelayanan dan kepuasan konsumen menggunakan uji kolmogorov-samirov dibantu dengan SPSS 23 dapat dilihat pada Tabel 4.

Tabel 4

Hasil SPSS 23 Analisis Uji Normalitas

\begin{tabular}{llr}
\hline \multicolumn{3}{c}{ One-Sample Kolmogorov- } \\
& \multicolumn{2}{c}{ Smirnov Test } \\
$\mathrm{N}$ & \multicolumn{1}{c}{ Unstandardized Residual } \\
Normal Parameters ${ }^{\mathrm{a}, \mathrm{b}}$ & Mean & 60 \\
& Std. & .0000000 \\
& Deviation & 2.15831207 \\
Most Extreme & Absolute & .108 \\
Differences & Positive & .108 \\
& Negative & -.100 \\
Test Statistic & & .108 \\
Asymp. Sig. (2-tailed) & & $.079^{\mathrm{c}}$ \\
a. Test distribution is Normal. & \\
b. Calculated from data. & \\
c. Lilliefors Significance Correction. & \\
\hline
\end{tabular}

Sumber: hasil pengolahan data primer, 2020

Sig. (2-tailed) 0,079 atau 0,079 $>0,05$ maka keputusannya data kualitas pelayanan dan kepuasan konsumen berdistribusi normal.

Uji linieritas. Uji keliniearan regresi dibantu dengan SPSS 23 dapat dilihat pada Tabel

5.

Tabel 5

Hasil SPSS 23 Analisis Uji Keliniearan Regresi

\begin{tabular}{|c|c|c|c|c|c|c|c|}
\hline \multicolumn{8}{|c|}{ ANOVA Table } \\
\hline \multirow{9}{*}{$\begin{array}{l}\text { Kepuasan } \\
\text { Pelanggan * } \\
\text { Kualitas } \\
\text { Pelayanan }\end{array}$} & & & Sum of & $\mathrm{df}$ & Mean & $\mathrm{F}$ & Sig. \\
\hline & & & Squares & & Squar & & \\
\hline & Betwe & (Combined) & 32.793 & 10 & 3.279 & 656 & 759 \\
\hline & en & Linearity & 2.891 & 1 & 2.891 & .578 & .451 \\
\hline & Group & Deviation & 29.902 & 9 & 3.322 & .665 & .736 \\
\hline & $\mathrm{s}$ & from & & & & & \\
\hline & & Linearity & & & & & \\
\hline & Withir & Iroups & 244.939 & 49 & 4.999 & & \\
\hline & Total & & 277.731 & 59 & & & \\
\hline
\end{tabular}

Sumber: hasil pengolahan data primer, 2020 
Tabel 5 merupakan rangkuman dari hasil analisis uji keliniearan regresi dengan jenis Pelayanan, dan Kepuasan, Sintang data $\mathrm{n}=60$ pada tingkat signifikasi $\alpha=0,05$ maka diperoleh Deviation from Linearity $=0,736$ maka $0,736>0,05$ maka regresi berpola linear.

Uji Homogenitas. Hasil analisis pra syarat (uji homogenitas) data hasil angket kualitas pelayanan dan kepuasan konsumen menggunakan uji Harley dibantu dengan SPSS 23 dapat dilihat pada Tabel 6.

Tabel 6.

Hasil SPSS 23 Analisis Uji Homogenitas

\begin{tabular}{cccc}
\hline \multicolumn{4}{c}{ Test of Homogeneity of Variances } \\
\hline KEPUASAN PELANGGAN & df2 & Sig. \\
Levene Statistic & df1 & 49 & .063 \\
2.285 & 8 &
\end{tabular}

Sumber: hasil pengolahan data primer, 2020

Tabel 6 menunjukkan hasil analisis uji homogenitas dengan df1 $=8$ dan df $2=49$ pada tingkat signifikasi $\alpha=0,05$ maka $0,063>0,05$ seghigga variansi kedua variabel yang dihubungkan bersifat homogen.

\section{Uji Regresi}

Analisis pada model regresi sederhana di bantu menggunakan SPSS 23. Hasil analisis regresi diperoleh tingkat sig sebesar 0,024 dan ini lebih kecil dari standar error 0,05 atau 5\% sehingga dinyatakan Ha diterima dengan asumsi bahwa variabel bebas mempengaruhi varibael terikat. Hal ini menunjukan bahwa penelitian ini dapat membuktikan secara empiris kualitas layanan berpengaruh terhadap kepuasan konsumen Di Toko Intan Market Lintas Melawi Sintang. Hasil analisis juga menunjukan bahwa pengaruh tersebut bersifat positif dengan koefisien corelasi 0,538 dengan tingkat keeratan sedang. Hasil analisis tersebut dapat dijabarkan secara singkat bahwa semakin baik kualitas layanan maka semakin meningkat pula kepuasan pelanggan. Hal tersebut didukung oleh hasil penelitian yang dilakukan oleh Jodi (2016) yang menemukan bahwa "Kualitas yang terdiri dari tangible, reliability, asurance, responsiveness, dan empathy berpengaruh signifikan terhadap kepuasan konsumen".

Tidak hanya kualitas menyebabkan kepuasan pelangan saja namun lebih dari itu. Kepuasan pelanggan memiliki pengaruh yang besar terhadap loyalitas pelanggan 
(Kusumasasti dkk, 2017). Hal ini dapat mengabarkan besarnya dampak dari kualitas

Pelayanan, dan

Kepuasan,

Sintang

Market Lintas Melawi Sintang diketahui besaran pengaruh kualitas layanan terhadap kepuasan konsumen ditampilkan pada tabel berikut:

Tabel 7

Hasil SPSS 23 Analisis Determinasi

\begin{tabular}{|c|c|c|c|c|}
\hline \multicolumn{5}{|c|}{ Model Summary $^{\mathbf{b}}$} \\
\hline Model & $\mathrm{R}$ & R Square & Adjusted R Square & $\begin{array}{l}\text { Std. Error of } \\
\text { the Estimate }\end{array}$ \\
\hline 1 & $.602^{\mathrm{a}}$ & .362 & .665 & 2.177 \\
\hline \multicolumn{5}{|c|}{ a. Predictors: (Constant), kualitas pelayanan } \\
\hline
\end{tabular}

Sumber: hasil pengolahan data primer, 2020

Tabel 7 menunjukkan hasil analisis menggunakan rumus koefisien determinasi dengan jenis data $r_{x y}$ sebesar 0,602 maka diperoleh koefisien determinasi sebesar $36,02 \%$. Besarnya sumbangan variabel bebas terhadap variabel terikat sebesar $36,02 \%$ sedangkan sisanya sebesar $63,8 \%$ ditentukan oleh variabel lain. Hal ini terlihat bahwa layanan yang diberikan melalui karyawann dapat memuaskan pelayanan sehingga pelangan akan meningkatkan intensitas konsumsinya bahkan menciptakan pembelian berulang. Ini senada dengan yang diungkapkan oleh meningkatkan kualitas layanan maka akan meningkatkan keputusan konsumen untuk melakukan pembelian berulang (Syahputra dkk, 2019).

Hal yang menjadi pertanyaan setelah melihat besarnya efek kualitas layanan adalah bagimana konsumen kualitas layanan yang baik dengan yang tidak. Ternyata Menurut Ahmadi (2013) jika kualitas layanan yang dirasakan sama oleh konsumen atau melebihi kualitas layanan yang diharapkan maka layanan tersebut dikatakan berkualitas dan memuaskan. Selain itu perlu menjadi perhatian bahwa Kulitas layanan yang baik memberikan efek yang baik bagi dunia usaha untuk tetap bertahan dalam persaingan usahan baik secara regional maupun global. Kelancaran usaha sangat tergantung bagimana dunia usaha dapat mempertahankan jumlah konsumen atau bahkan meningkatkan konsumen. Hal ini menjadi tantangan tersendiri bagi dunia usaha saat ini. 


\section{Kesimpulan}

Kualitas

Pelayanan, dan

Kepuasan,

Sintang

Berdasarkan hasil analisis dan uji hipotesis yang dilakukan dalam penelitian maka dapat disimpulkan bahwa kualitas layanan berpengaruh secara positif terhadap

kepuasan konsumen. Semakin baik kualitas layanan maka konsumen akan semakin puas dan hasil akhirnya menjadi konsumen royal.

Saran

Terkhusus unit usaha Toko Intan Market dan sejenisnya dapat memperhatiakan kulitas layanan yang masih dalam katagori cukup ini untuk di tingkatkan. Selain itu perhatikan faktor eksternal misalnya diskon, bazar, promo di tempat lainnya yang akan mempengaruhi jumlah konsumen.

\section{DAFTAR PUSTAKA}

Ahmadi, Herman. 2013. Analisis Pengaruh Harga dan Kualitas Layanan Terhadap Minat Beli Ulang Gas Elpiji $3 \quad \mathrm{Kg}$ dalam Meningkatkan Citra Perusahaan. Jurnal Dosen STIE Dharma Iswara, 2(1), Hal: 77-89.

Hardiyansyah, 2011. Kualitas Pelayanan Publik. Yogyakarta: Gava Media.

Jodi, IWGAS. 2016. Pengaruh Kualitas Pelayanan dan Kebijakan Penjualan Terhadap Kinerja Pemasaran dan Kepuasan Konsumen PT Wahana Wirawan Nissan. Jurnal Ekonomi dan Bisnis, 3(2), Hal: 22-34.

Keller, L. 2008. Manajemen Pemasaran. Jakarta: Erlangga.

Kusumasasti Ika., Andarwati Dan Hadiwidjojo Djumilah. 2017. Pengaruh Kualitas Produk Dan Layanan Terhadap Loyalitas Pelanggan Coffee Shop. EKOBIS, 22(2), Hal 123129.

Mahmudi. 2015. Manajemen Kinerja Sektor Publik. Yogyakarta: Sekolah Tinggi Ilmu Manajemen YKPN.

Ranto Dwi Wahyu Pril. 2017. Pengaruh Citra Toko Terhadap Kepuasan Pelanggan Dan Loyalitas Pelanggan Di Yogyakarta. JBMA, IV(2), Hal: 1-11.

Sugiyono. 2015. Metode Penelitian Kuantitatif Kualtatif dan R \& D. Bandung: Afabeta.

Suharyadi Dedi. 2018. Analisis Pengaruh Kualitas Pelayanan Terhadapkepuasan Pelanggan Pada Toko Yoehan Wanaherang Bogor. Jurnal Ilmu Pengetahuan Dan Teknologi Komputer, 3(2), Hal: 289-296.

Syahputra Dedi., Alvi Alvi Firwati., Dan Garnasih Raden Lestari. Analisis Kualitas Layanan Dan Citra Merek Terhadap Pembelian Berulang Dengan Harga Sebagai Variabel Moderasi Pada Maskapai Penerbangan Rute Pekanbaru Jakarta. Jurnal Ekonomi KIAT, 30(2), Hal: 14-30.

Tjiptono, F. 2014. Pemasaran Jasa-Prinsip, Penerapan, dan Penelitian. Yogyakarta: CV. Andi Offset.

Yamit, Z. 2002. Manajemen Kualitas Produk dan Jasa. Yogyakarta: Ekonisia. 